\title{
Lower Urinary Tract Symptoms: Prevalence and Factors Associated with Help-Seeking in Male Primary Care Attendees
}

\author{
Noor Mikraz Mohamad Isa ${ }^{1,2}$, Aznida Firzah Abdul Aziz ${ }^{1, *}$ \\ 'Department of Family Medicine, Faculty of Medicine, Universiti Kebangsaan Malaysia Medical Centre, Kuala Lumpur, Malaysia \\ ${ }^{2}$ Ministry of Health Malaysia, Putrajaya, Malaysia
}

\begin{abstract}
Background: Lower urinary tract symptoms (LUTS) are common among elderly men. However, seeking help for this problem is mostly delayed until complications arise. Primary care clinics serve as the first point of contact for a person's health needs throughout their life. This study aimed to determine the prevalence of LUTS among primary care attendees, and the factors that influence seeking medical intervention at primary care clinics.

Methods: Using a universal sampling technique, 460 male patients aged 60 and above visiting an urban based public primary care clinic were recruited. An interviewer administered the questionnaire which used International Prostate Symptoms Score and International Consultation on Incontinence Modular Questionnaire-Lower Urinary Tract Symptoms-Quality of Life.

Results: The prevalence of any LUTS and clinically significant LUTS were $89.8 \%$ and $20.5 \%$, respectively. Among the 385 participants who completed the study, only $41.8 \%$ had consulted a doctor for LUTS. Among those with moderate/severe symptoms only $57.6 \%$ had sought medical intervention. Multiple logistic regression analysis showed that the presence of more than two comorbidities $(\mathrm{P}=0.004$; odds ratio $[\mathrm{OR}], 4.695 ; 95 \%$ confidence interval $[\mathrm{CI}], 1.632-13.508)$ and quality of life ( $\mathrm{P}=0.002$; $\mathrm{OR}, 1.271 ; 95 \% \mathrm{CI}, 1.091-1.481)$ were independent factors significantly associated with seeking help.

Conclusion: Prevalence of LUTS among elderly men undergoing primary care is high, but more than half of the patients had not sought medical attention. Increasing comorbidities and impact on quality of life influenced elderly men with LUTS to seek help.
\end{abstract}

Keywords: Lower Urinary Tract Symptoms; Help-Seeking Behavior; Primary Care; General Practitioners

Received: February 12, 2019, Revised: August 14, 2019, Accepted: September 5, 2019

*Corresponding Author: Aznida Firzah Abdul Aziz https://orcid.org/0000-0001-7620-4008

Tel: +60-3-9145-6117, Fax: +60-3-9145-9479, E-mail: draznida@ppukm.ukm.edu.my

'Parts of this study were presented as a poster presentation at the 20th Malaysian Family Medicine Scientific Association Scientific Conference, held on 2nd5th August 2017 at Hotel Equatorial, Penang. 


\section{INTRODUCTION}

Lower urinary tract symptoms (LUTS) encompass a range of symptoms that result from conditions and diseases affecting the bladder, prostate and urethra. ${ }^{1)}$ It appears that LUTS are highly prevalent among aging men worldwide and are often associated with benign prostatic hyperplasia. $^{2-4)}$ The growing body of evidence also found that moderate to severe symptoms have been associated with higher morbidity and a poorer quality of life..$^{5-7)}$

In the study of Irwin et al., ${ }^{8)}$ an estimated 2.3 billion individuals will be affected by at least one LUTS by year 2018. Despite the high prevalence worldwide and its association with significant health problems among men, the rate of seeking medical advice is consistently low, and mostly at advanced stages of the disease. ${ }^{9-11)}$ The way men react towards their health is greatly influenced by societal expectations.

In Malaysia, which is a multi-ethnic nation, different cultures and beliefs invariably influence the practice of seeking help. Among some ethnic groups, adopting a healthy lifestyle comes naturally; while in some groups, seeking help can be perceived as demonstrating weakness or a threat to their masculinity. ${ }^{12)}$ The available literature mainly focuses on the factors that influence men seeking treatment for LUTS and most studies were done at a tertiary level. Disease severity and considering LUTS as "bothersome" are found to be among the most common reasons for men consulting their doctors. ${ }^{10,11,13-17)}$ Local literature on factors which prompt patients to seek early medical intervention from primary care providers when they experience LUTS is scarce. However, in studies done in the West and other Asian countries among primary care attendees, respondents mainly considered LUTS as "part of normal aging process," ${ }^{14,18-20)}$ and embarrassment to discuss sexual or urinary problems appears to be among the identified barriers to seeking medical intervention. ${ }^{9,14,18)}$ Simple and effective treatments are available at the primary care level when symptoms are detected early, and help to improve the quality of life.

Hence, this study aims to determine the factors that influence elderly men in seeking treatment for LUTS in a primary care setting, with a focus on those who are symptomatic but had not sought any intervention despite having access to healthcare services.

\section{METHODS}

\section{Study Design and Participants}

The study was conducted at Klinik Kesihatan Seremban, an urbanbased public primary care health center, located approximately $60 \mathrm{~km}$ south of the administrative capital of Malaysia, between June to October 2016. Using the universal sampling method, 460 men aged 60 and above, who attended the clinic during the study period to seek any treatment for themselves, for prescription refills, or for physiotherapy sessions at the health center, were recruited for the study.

The participants were first screened for LUTS using the validated International Prostate Symptoms Score (IPSS) questionnaire. IPSS is an eight-item questionnaire in which the first seven questions assess the severity of incomplete emptying, urinary frequency, intermittency, urgency, weak stream, and nocturia, each referring to the prior month. Each symptom involves the assignment of a score from 1 to 5 for a maximum of 35 points. A score of $0-7$ is rated as mildly symptomatic, 8-19 is moderately symptomatic, and 20-35 is severely symptomatic. The 8th question (i.e., "bothersome" score) assesses the degree of bother and dissatisfaction associated with the symptoms. This score is ranges from 0 (delighted) to 6 (terrible). Options $0-2$ were collectively grouped as 'satisfied,' option 3 was 'equally satisfied and dissatisfied,' options 4-6 were collectively grouped as 'dissatisfied.' "Bother" was defined as patients who were 'dissatisfied' with their individual symp-

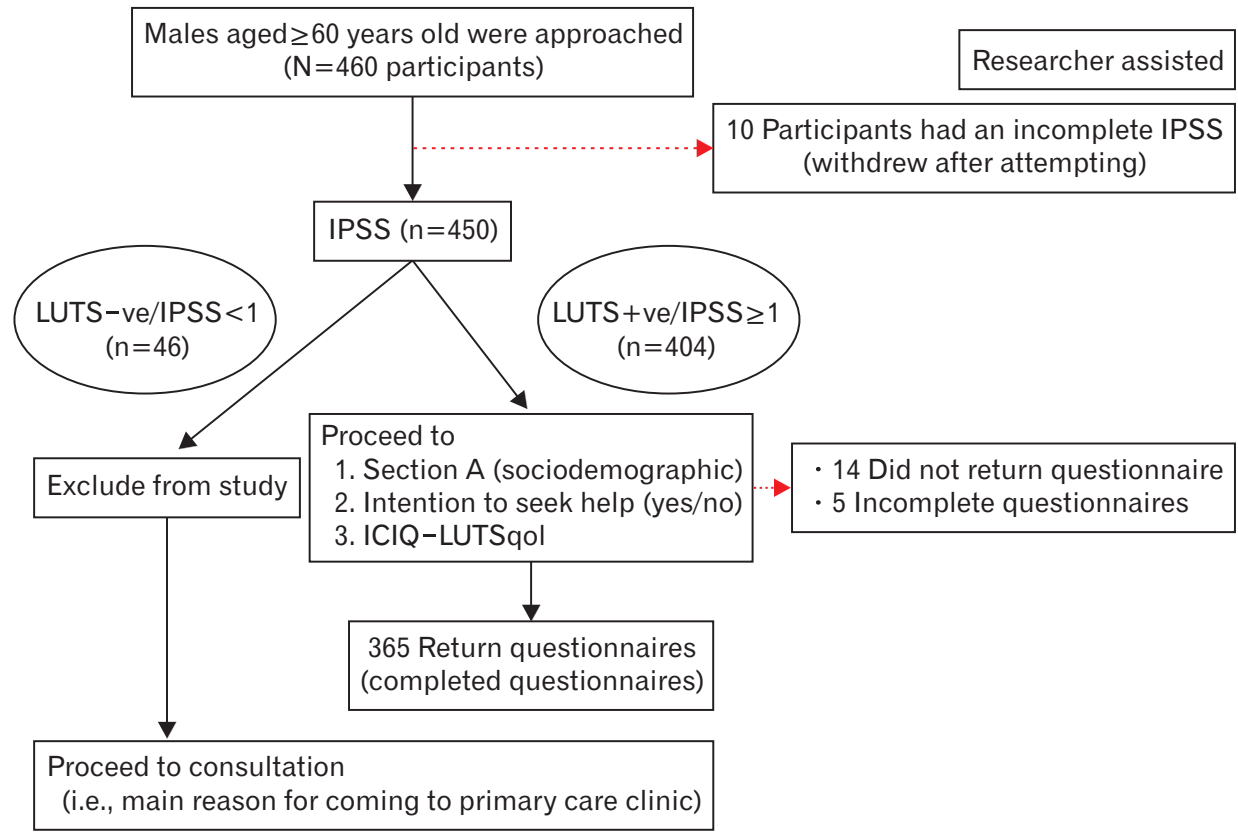

Figure 1. Study flow chart. IPSS, International Prostate Symptoms Score; LUTS, Iower urinary tract symptoms; ICIQ-LUTSqol, Incontinence Modular Questionnaire-Lower Urinary Tract Symptoms-Quality of Life. 
toms. ${ }^{21)}$ Both English and translated Malay versions of IPSS have been validated in the local population with a Cronbach $\alpha$ value of more than $0.5 .^{22,23)}$

The group of participants without LUTS (i.e., who scored zero in the IPSS) or those who were unable to comprehend English or Malay were excluded from this study. Participants who scored at least one in the IPSS (IPSS $\geq 1$ ) were included in the study, and asked to complete questions on their demographic and clinical profile, quality of life (using the International Consultation on Incontinence Questionnaire Lower Urinary Tract Symptoms Quality of Life, ICIQ-LUTSqol questionnaire), and one question on whether they had sought help from doctor for their LUTS (yes or no). ICIQ-LUTSqol is a detailed measure that assesses the impact of urinary symptoms on quality of life. Both English and Malay versions have been validated with a Cronbach $\alpha$ value of more than $0.90 .{ }^{24)}$ Participants were asked nineteen questions assessing the following domains: role limitation, physical limitation, social limitation, personal relationships, emotional effects, and sleep and energy. Participants were asked to grade the extent of the limitation: 0 (not relevant), 1 (not at all), 2 (slightly), 3 (moderate), and 4 (a lot). The overall scores ranged from 19-76, with greater values indicating an increased impact on quality of life.

A pilot study was conducted beforehand to ensure that lay people understood the questions being asked. This study was initially intended to be self-administered, but during the pilot study, it was noted that more than half of the participants asked to have the questionnaire be read to them as majority claimed that they were visually challenged or had forgotten to bring their reading glasses with them. Hence, the reason for using trained interviewers during the actual recruitment. A total of three trained interns interviewed the eligible men and the text was standardized in English and Malay. The flow of the study is summarized in Figure 1.

Table 1. Socio-demographic characteristics of the participants

\begin{tabular}{lcrr}
\hline \multicolumn{1}{c}{ Characteristic } & Overall & Sought help & Did not seek help \\
\hline Total & 385 & $161(41.8)$ & $224(58.2)$ \\
Age group (y) & & & \\
$\quad 60-69$ & $262(68.0)$ & $103(39.3)$ & $159(60.7)$ \\
$\geq 70$ & $123(32.0)$ & $58(47.2)$ & $65(52.8)$ \\
Marital status & & & \\
$\quad$ Married & $373(96.9)$ & $155(41.6)$ & $218(58.4)$ \\
$\quad$ Unmarried & $12(3.1)$ & $6(50.0)$ & $6(50.0)$ \\
Employment & & & \\
$\quad$ Working & $45(11.7)$ & $16(35.6)$ & $29(64.4)$ \\
$\quad$ Not working & $340(88.3)$ & $145(42.6)$ & $195(57.4)$ \\
Education & & & \\
$\quad$ Up to secondary level & $329(85.4)$ & $136(41.3)$ & $193(58.7)$ \\
$\quad$ Tertiary level & $56(14.6)$ & $25(44.6)$ & $31(55.4)$ \\
Ethnicity & & & \\
$\quad$ Malay & $121(31.4)$ & $55(45.5)$ & $66(54.5)$ \\
$\quad$ Chinese & $96(24.9)$ & $27(28.1)$ & $69(71.9)$ \\
$\quad$ Indian & $155(40.3)$ & $72(46.5)$ & $83(53.5)$ \\
$\quad$ Others & $13(3.4)$ & $7(53.8)$ & $6(46.1)$ \\
\hline
\end{tabular}

Values are presented as number (\%).

\section{Statistical Analysis}

Data were analyzed using the IBM SPSS software ver. 25.0 (IBM Corp., Armonk, NY, USA). The chi-square test was used to determine the association between categorical data and the t-test for continuous data. Variables which were found to have a statistically significant association $(\mathrm{P}<0.05)$ during univariate analysis and any other factors which have been identified to be significant in previous studies were selected for multivariate logistic regression analysis as tools in studying the associations between various factors and help seeking behavior for LUTS.

\section{Ethical Approval}

Ethical approval to conduct this study was obtained from the Universiti Kebangsaan Malaysia Ethics Committee (research ID no., FF-2016229), the Medical Research and Ethics Committee (MREC) Ministry of Health Malaysia (NMRR-16-352-29488).

Written consent was also obtained from all participants involved in the study.

\section{RESULTS}

Four hundred and sixty participants were approached. Out of these, 450 completed the IPSS questionnaire (the denominator for the LUTS prevalence). However, of the remaining 450, only 385 participants managed to complete all sections in the survey (sociodemographic profile, intention to seek and ICIQ-LUTS-Qol). Data from these 385

Table 2. Clinical characteristics and quality of life of the participants ( $N=385$ )

\begin{tabular}{|c|c|c|c|}
\hline Characteristic & Overall & Sought help & $\begin{array}{l}\text { Did not seek } \\
\text { help }\end{array}$ \\
\hline Total & & $161(41.8)$ & $224(58.2)$ \\
\hline \multicolumn{4}{|l|}{ Diabetes mellitus } \\
\hline Absent & 193 & 88 & 105 \\
\hline Present & 192 & 73 & 119 \\
\hline \multicolumn{4}{|l|}{ Hypertension } \\
\hline Absent & 103 & 42 & 61 \\
\hline Present & 282 & 119 & 163 \\
\hline \multicolumn{4}{|l|}{ Prostate disease } \\
\hline Absent & 316 & 100 & 216 \\
\hline Present & 69 & 61 & 8 \\
\hline \multicolumn{4}{|l|}{ Co-morbidity } \\
\hline Two and less & $265(68.8)$ & $99(37.4)$ & $166(62.6)$ \\
\hline More than two & $120(31.2)$ & $62(51.7)$ & $58(48.3)$ \\
\hline \multicolumn{4}{|l|}{ Symptoms severity (IPSS) } \\
\hline Mild (1-7) & $293(76.1)$ & $108(36.9)$ & $185(63.1)$ \\
\hline Moderate-severe (8-35) & $92(23.9)$ & $53(57.6)$ & $39(42.4)$ \\
\hline \multicolumn{4}{|l|}{ Bothersome } \\
\hline Satisfied/mixed (IPSS $\geq 8: 3$ ) & $355(92.2)$ & 139 (39.2) & $216(60.8)$ \\
\hline Dissatisfied (IPSS <8: 3) & $30(7.8)$ & $22(73.3)$ & $8(26.7)$ \\
\hline $\begin{array}{l}\text { Quality of life (ICIQ-LUTSqol, } \\
\text { median [IQR]) }\end{array}$ & $19(3)$ & $20(3)$ & $19(2)$ \\
\hline
\end{tabular}


participants were further analyzed to find the association of those various factors and help-seeking.

The overall median age of the study population was 67 years old (interquartile range, 9). Majority of the participants were from the age group 60 to 69 years old (68\%), married (96.9\%), not working (88.3\%), and had an educational attainment up to the secondary level (63.6\%).

Compared to the national population statistic (25), our study population had a higher proportion of Indians (40.3\%), followed by Malays (31.4\%), and Chinese (24.9\%). $68.8 \%$ of the participants had less than three comorbidities (Tables 1, 2).

\section{Prevalence of Lower Urinary Tract Symptoms and Its Severity}

From the 450 participants who completed the IPSS questionnaire, 46 (10.2\%) had no symptoms, 312 (69.3\%) had mild symptoms, 79 (17.6\%) had moderate symptoms, and $13(2.9 \%)$ had severe symptoms. The prevalence of any LUTS (IPSS $\geq 1$ ) was $89.8 \%(404 / 450)$ and the prevalence of clinically significant LUTS (defined as IPSS $\geq 8$ ) was $20.5 \%$.

\section{Help-Seeking Behavior for Lower Urinary Tract Symptoms} Help-seeking behavior was defined as a participants' self-driven decision to seek medical help for their LUTS. ${ }^{21)}$ Overall, we found that 224 (58.2\%) of the participants with positive LUTS had never discussed their urinary symptoms with their doctor. Interestingly, even those with moderate to severe LUTS, there were still 39 participants (42.4\%) who did not seek help or consult a medical practitioner for their symptoms.

We then further analyzed the moderate to severe LUTS group to look for the factors associated with seeking help. Ethnicity, co-morbidity, degree of bother, and quality of life were found to be significantly

Table 3. Association between socio-demographic characteristics and help-seeking among participants with moderate to severe lower urinary tract symptoms ( $\mathrm{N}=92)$

\begin{tabular}{|c|c|c|c|c|}
\hline Variable & Overall & Sought help & $\begin{array}{l}\text { Did not seek } \\
\text { help }\end{array}$ & P-value* \\
\hline Total & & $53(57.6)$ & $39(42.4)$ & \\
\hline Age group (y) & & & & 0.632 \\
\hline $60-69$ & $66(71.7)$ & $37(56.1)$ & $29(43.9)$ & \\
\hline$\geq 70$ & $26(28.3)$ & $16(61.5)$ & $10(38.5)$ & \\
\hline Marital status & & & & $1.000^{\dagger}$ \\
\hline Married $^{\dagger}$ & 88 (95.7) & $51(58.0)$ & $37(42.0)$ & \\
\hline Unmarried & $4(4.3)$ & $2(50.0)$ & $2(50.0)$ & \\
\hline Employment & & & & $1.000^{\dagger}$ \\
\hline Working & $9(9.8)$ & 5 (55.6) & $4(44.4)$ & \\
\hline Not working & 83 (90.2) & $48(57.8)$ & 35 (42.2) & \\
\hline Educational attainment & & & & 0.872 \\
\hline Up to secondary level & 70 (76.1) & $40(57.1)$ & $30(42.9)$ & \\
\hline Tertiary & $22(23.9)$ & $13(59.1)$ & $9(40.9)$ & \\
\hline Ethnicity & & & & 0.016 \\
\hline Malay & $29(31.5)$ & $22(75.9)$ & 7 (24.1) & \\
\hline Non-Malay & $63(68.5)$ & $31(49.2)$ & $32(50.8)$ & \\
\hline
\end{tabular}

Values are presented as number (\%) or number, unless otherwise stated.

*By chi-square test; a P-value $<0.05$ is statistically significant. 'By Fischer's exact test. associated with seeking help in this study as their P-values were less than 0.05 (Tables 3, 4).

However, after adjusting the variables in the logistic regression, we found that only the comorbidity and quality of life scores were proven to be significant independent predictors for seeking help or medical intervention. Those with more than two comorbidities and a poorer quality of life (higher score in ICIQLUTSqol) were more likely to seek help for LUTS with $\mathrm{P}=0.004$ (odds ratio [OR], 4.695; 95\% confidence interval [CI], 1.632-13.508) and P=0.002 (OR, 1.271; 95\% CI, 1.091-1.481), respectively (Table 5).

\section{DISCUSSION}

To our knowledge this is the first study conducted on elderly men with LUTS visiting a primary care clinic in Malaysia. Of this study's participants, which included 385 elderly men aged 60 years and above at an urban government health clinic, $89.8 \%$ and $20.5 \%$ showed the symptoms of LUTS and clinically significant LUTS, respectively. Our study suggests a similar overall prevalence rate of LUTS, but a higher prevalence of moderate to severe symptoms, compared to an earlier population-based study conducted in the northern region of Malaysia which reported the prevalence as $87.8 \%$ and $6.2 \%$, respectively. ${ }^{25}$

For comparison, the prevalence of clinically significant LUTS in males above 60 years old (which is 20.5\%) in our study is lower than the age-specific prevalence quoted in other studies $(26.8 \%$ in Singapore $^{21)}$ and $33.6 \%$ in Denmark. ${ }^{26)}$ This difference could be because these studies were conducted in developed countries which had higher proportions of elderly persons due to longer life expectancy compared to Malaysia. Many studies also reported that the severity of LUTS worsens with advancing age. , $^{2,42,27)}$

Table 4. Association between clinical characteristics and quality of life with helpseeking among participants with moderate to severe lower urinary tract symptoms $(\mathrm{N}=92)$

\begin{tabular}{|c|c|c|c|c|}
\hline Variable & Overall & Sought help & $\begin{array}{l}\text { Did not seek } \\
\text { help }\end{array}$ & P-value \\
\hline Total & & $53(57.6)$ & $39(42.4)$ & \\
\hline Co-morbidity & & & & $0.023^{*}$ \\
\hline Two and less & $56(60.9)$ & 27 (48.2) & $29(51.8)$ & \\
\hline More than two & $36(39.1)$ & $26(72.2)$ & $10(27.8)$ & \\
\hline Bothersome & & & & $0.032^{*}$ \\
\hline $\begin{array}{l}\text { Satisfied/mixed } \\
\text { (IPSS } \geq 8: 3)\end{array}$ & 70 (76.1) & $36(51.4)$ & $34(48.6)$ & \\
\hline $\begin{array}{l}\text { Dissatisfied } \\
\quad(\text { IPSS <8: 3) }\end{array}$ & $22(23.9)$ & $17(77.3)$ & $5(22.7)$ & \\
\hline $\begin{array}{l}\text { Symptoms severity score } \\
\text { (total IPSS, median [IQR]) }\end{array}$ & $12(7)$ & $12(8)$ & $11(6)$ & $0.706^{\dagger}$ \\
\hline $\begin{array}{l}\text { Quality of life (ICIQ-LUTSqol, } \\
\text { median [IQR]) }\end{array}$ & $21(6)$ & $23(9)$ & $20(3)$ & $0.002^{\dagger}$ \\
\hline
\end{tabular}

Values are presented as number (\%) or number, unless otherwise stated. IPSS, International Prostate Symptoms Score; IQR, interquartile range; ICIQ-LUTSqol, Incontinence Modular Questionnaire-Lower Urinary Tract Symptoms-Quality of Life. *By chi-square test; a P-value $<0.05$ is statistically significant. ${ }^{\dagger}$ By Mann-Whitney U-test; a P-value $<0.05$ is statistically significant. 
Table 5. Factors which influence help-seeking among elder men with clinically significant lower urinary tract symptoms ( $N=92)$

\begin{tabular}{|c|c|c|c|c|c|c|c|}
\hline Variable & B & Standard error & Wald & $\begin{array}{l}\text { Degrees of } \\
\text { freedom }\end{array}$ & Significance & $\operatorname{Exp}(B)$ & $\begin{array}{l}\text { 95\% confidence interval } \\
\text { for Exp(B) }\end{array}$ \\
\hline \multicolumn{8}{|l|}{ Ethnicity } \\
\hline Malay & & & & & & 1 & \\
\hline Non-Malay & -0.991 & 0.555 & 3.189 & 1 & 0.074 & 0.371 & $0.125-1.01$ \\
\hline \multicolumn{8}{|l|}{ Co-morbidity } \\
\hline Two and less ( $\leq 2)$ & & & & & & 1 & \\
\hline More than two (>2) & 1.547 & 0.539 & 8.229 & 1 & 0.004 & 4.695 & $1.632-13.508$ \\
\hline \multicolumn{8}{|l|}{ Bothersome } \\
\hline Satisfied/mixed & & & & & & 1 & \\
\hline Dissatisfied & 0.172 & 0.691 & 0.062 & 1 & 0.803 & 1.188 & $0.306-4.607$ \\
\hline Quality of life score & 0.240 & 0.078 & 9.429 & 1 & 0.002 & 1.271 & $1.091-1.481$ \\
\hline Total IPSS & -0.041 & 0.057 & 0.521 & 1 & 0.470 & 0.960 & $0.859-1.073$ \\
\hline Constant & -4.467 & 1.620 & 7.599 & 1 & 0.006 & 0.011 & \\
\hline
\end{tabular}

Model explained between 26.5\% (Cox and Snell $\mathrm{R}^{2}$ ) and 35.7\% (Nagelkerke $\mathrm{R}^{2}$ ) of the variance in help-seeking, and correctly classified $71.7 \%$ of cases. $\chi^{2}(5, \mathrm{~N}=92)=28.361$, $P<0.001$. Figures in bold are statistically significant.

IPSS, International Prostate Symptoms Score.

In terms of seeking help, the prevalence of men with LUTS who had sought help was higher compared to other countries (which ranged between $10 \%-30 \%)^{9,11,21,26,28)}$ This could be attributed to the differences in healthcare policies which may have influenced patient motivation for help-seeking. In Malaysia, the medical treatment fee is fully subsidized by the government for all Malaysians aged 60 and above. Hence, despite being offered a free healthcare system, the $41.8 \%$ prevalence of help seeking observed in this study is considered very low.

It is well-established that increasing symptom severity has a negative effect on quality of life. ${ }^{9,26)}$ Those with clinically significant LUTS were also found to have increased risk of developing sexual disorders (such as erectile/ejaculatory disorders), ${ }^{4)}$ mental health problems (mainly anxiety and depression), ${ }^{27)}$ and the risk of having fall. ${ }^{29)}$ Surprisingly, $42.4 \%$ of those with moderate to severe symptoms had yet to seek help, up to the time our study was conducted.

Previous studies reported that increasing age, symptom severity, degree of bother of symptoms, and quality of life were associated with seeking help. ${ }^{11,17,21)}$ In contrast to our study, age and symptom severity were not found to be significantly associated with seeking help among those with clinically significant symptoms. A possible reason could be the small differences in the median score for IPSS between the "sought help" and "did not seek help" groups.

However, apart from the worsening quality of life, our study also found that those who were having more than two co-morbid conditions and Malays were more likely to seek help. Those with more comorbid conditions probably had more frequent visits to the health clinic and hence, more opportunities to express their problems to their doctors during consultations.

Cultural differences and variations in the histology of the benign prostatic hyperplasia might explain the variability in the symptoms among different ethnicities. A local study by Lim et al., ${ }^{30)}$ conducted during a prostate awareness campaign, noted an independent association between severity of LUTS and ethnicity. The study reported that Malay men were found to have moderate to severe LUTS and were more bothered by the symptoms compared to Chinese and Indians. Apart from that, we postulate that varying cultural acceptance and religious rituals, and adaptation to the urinary symptoms may have influenced the decision to seek help. Hence, further studies are needed to explore the influence of cultural perspectives on the decision to seek help of LUTS patients.

\section{Limitations and Recommendation}

We acknowledge that this study had several limitations. First, this study had a sample from an urban primary care health clinic, and the study population had a higher-than-average proportion of Indian respondents compared to major ethnic Malays in the country. Thus, we cannot generalize our findings for the general population. It is recommended that a multicenter trial, with better sampling proportions of representative ethnic groups, be conducted in future.

Furthermore, to date there is no published local study that assesses barriers to seeking medical intervention among men with LUTS. A qualitative study is recommended to explore the socio-cultural barriers that may influence our multi-ethnic population and their decision to actively seek medical intervention for LUTS.

\section{Conclusions}

In summary, the results of this study show that prevalence of LUTS among elderly men visiting primary care clinic is high. However, the rate of seeking treatment is still low. Ethnicity, comorbidity, symptoms, degree of bother, and quality of life were each associated with seeking help. However, after controlling all these factors, only comorbid conditions and quality of life were found as independent factors significantly associated with seeking help.

Primary care providers play an important role in screening for LUTS. They also need to be more proactive in educating the public about LUTS and creating awareness about the available treatment options. As LUTS adversely affects the individual's quality of life, it is important to emphasize the importance of seeking early medical intervention at 
the early stages of the disease.

\section{CONFLICT OF INTEREST}

No potential conflict of interest relevant to this article was reported.

\section{ACKNOWLEDGMENTS}

We would like to acknowledge the contributions from associate professor Dr. Christopher Ho Chee Kong (former consultant urologist, Department of Surgery, University Kebangsaan Malaysia Medical Centre) and professor Dr. Tong Seng Fah (Department of Family Medicine, Universiti Kebangsaan Malaysia Medical Centre) for their contribution to the project.

We would like to acknowledge the permission given to conduct this study and support accorded by the state health director of Negeri Sembilan, District Health Officer of Seremban, and the Family Medicine Specialist of Klinik Kesihatan Seremban. We also thank the director general of Ministry of Health Malaysia for giving permission to publish this study.

\section{ORCID}

Noor Mikraz Mohamad Isa: https://orcid.org/0000-0001-7857-7684

Aznida Firzah Abdul Aziz: https://orcid.org/0000-0001-7620-4008

\section{REFERENCES}

1. McVary KT, Roehrborn CG, Avins AL, Barry MJ, Bruskewitz RC, Donnell RF, et al. American Urological Association Guideline: management of benign prostatic hyperplasia (BPH). Linthicum (MD): American Urological Association; 2010.

2. Boyle P, Robertson C, Mazzetta C, Keech M, Hobbs FD, Fourcade R, et al. The prevalence of lower urinary tract symptoms in men and women in four centres: the UrEpik study. BJU Int 2003;92:409-14.

3. Coyne KS, Sexton CC, Thompson CL, Milsom I, Irwin D, Kopp ZS, et al. The prevalence of lower urinary tract symptoms (LUTS) in the USA, the UK and Sweden: results from the Epidemiology of LUTS (EpiLUTS) study. BJU Int 2009;104:352-60.

4. Li MK, Garcia LA, Rosen R. Lower urinary tract symptoms and male sexual dysfunction in Asia: a survey of ageing men from five Asian countries. BJU Int 2005;96:1339-54.

5. Chung RY, Leung JC, Chan DC, Woo J, Wong CK, Wong SY. Lower urinary tract symptoms (LUTS) as a risk factor for depressive symptoms in elderly men: results from a large prospective study in Southern Chinese men. PLoS One 2013;8:e76017.

6. Kannan H, Radican L, Turpin RS, Bolge SC. Burden of illness associated with lower urinary tract symptoms including overactive bladder/ urinary incontinence. Urology 2009;74:34-8.

7. Garraway WM, Russell EB, Lee RJ, Collins GN, McKelvie GB, Hehir M, et al. Impact of previously unrecognized benign prostatic hyperplasia on the daily activities of middle-aged and elderly men. Br J Gen Pract
1993;43:318-21.

8. Irwin DE, Kopp ZS, Agatep B, Milsom I, Abrams P. Worldwide prevalence estimates of lower urinary tract symptoms, overactive bladder, urinary incontinence and bladder outlet obstruction. BJU Int 2011; 108:1132-8.

9. Homma Y, Yamaguchi O, Hayashi K; Neurogenic Bladder Society Committee. Epidemiologic survey of lower urinary tract symptoms in Japan. Urology 2006;68:560-4.

10. Taylor J, McGrother CW, Harrison SC, Assassa PR; Leicestershire MRC Incontinence Study Team. Lower urinary tract symptoms and related help-seeking behaviour in South Asian men living in the UK. BJU Int 2006;98:605-9.

11. Lai UC, Wun YT, Luo TC, Pang SM. In a free healthcare system, why do men not consult for lower urinary tract symptoms (LUTS)? Asia Pac Fam Med 2011;10:7.

12. Galdas PM, Cheater F, Marshall P. Men and health help-seeking behaviour: literature review. J Adv Nurs 2005;49:616-23.

13. Trueman P, Hood SC, Nayak US, Mrazek MF. Prevalence of lower urinary tract symptoms and self-reported diagnosed 'benign prostatic hyperplasia, and their effect on quality of life in a community-based survey of men in the UK. BJU Int 1999;83:410-5.

14. Shaw C, Tansey R, Jackson C, Hyde C, Allan R. Barriers to help seeking in people with urinary symptoms. Fam Pract 2001;18:48-52.

15. Wolters R, Wensing M, van Weel C, van der Wilt GJ, Grol RP. Lower urinary tract symptoms: social influence is more important than symptoms in seeking medical care. BJU Int 2002;90:655-61.

16. Lammers HA, van Wijnhoven R, Teunissen TA, Harmsen S, LagroJanssen AL. Why do men suffering from LUTS seek primary medical care?: a qualitative study. J Eval Clin Pract 2015;21:931-6.

17. Apostolidis A, de Nunzio C, Tubaro A. What determines whether a patient with LUTS seeks treatment?: ICI-RS 2011. Neurourol Urodyn 2012;31:365-9.

18. Gannon K, Glover L, O'Neill M, Emberton M. Men and chronic illness: a qualitative study of LUTS. J Health Psychol 2004;9:411-20.

19. Horrocks S, Somerset M, Stoddart H, Peters TJ. What prevents older people from seeking treatment for urinary incontinence?: a qualitative exploration of barriers to the use of community continence services. Fam Pract 2004;21:689-96.

20. Teh GC, Sahabudin RM, Lim TC, Chong WL, Woo S, Mohan M, et al. Prevalence of symptomatic BPE among Malaysian men aged 50 and above attending screening during prostate health awareness campaign. Med J Malaysia 2001;56:186-95.

21. Chong C, Fong L, Lai R, Koh YT, Lau WK, Hartman M, et al. The prevalence of lower urinary tract symptoms and treatment-seeking behaviour in males over 40 years in Singapore: a community-based study. Prostate Cancer Prostatic Dis 2012;15:273-7.

22. Quek KF, Low WY, Razack AH, Sin Loh C, Chua CB. Reliability and validity of the Malay version of the International Prostate Symptom Score in the Malaysian population. J Urol 2002;167:1359-62.

23. Quek KF, Low WY, Razack AH, Loh CS. Reliability and validity of the International Prostate Symptom Score in a Malaysian population. BJU Int 2001;88:21-5.

24. Lim R, Liong ML, Lau YK, Yuen KH. Validity, reliability, and responsiveness of the ICIQ-UI SF and ICIQ-LUTSqol in the Malaysian population. Neurourol Urodyn 2017;36:438-42. 
25. Mariappan P, Chong WL. Prevalence and correlations of lower urinary tract symptoms, erectile dysfunction and incontinence in men from a multiethnic Asian population: results of a regional population-based survey and comparison with industrialized nations. BJU Int 2006;98: 1264-8.

26. Norby B, Nordling J, Mortensen S. Lower urinary tract symptoms in the danish population: a population-based study of symptom prevalence, health-care seeking behavior and prevalence of treatment in elderly males and females. Eur Urol 2005;47:817-23.

27. Coyne KS, Wein AJ, Tubaro A, Sexton CC, Thompson CL, Kopp ZS, et al. The burden of lower urinary tract symptoms: evaluating the effect of LUTS on health-related quality of life, anxiety and depression: Epi-
LUTS. BJU Int 2009;103 Suppl 3:4-11.

28. Sarma AV, Wallner L, Jacobsen SJ, Dunn RL, Wei JT. Health seeking behavior for lower urinary tract symptoms in black men. J Urol 2008;180: 227-32.

29. Parsons JK, Mougey J, Lambert L, Wilt TJ, Fink HA, Garzotto M, et al. Lower urinary tract symptoms increase the risk of falls in older men. BJU Int 2009;104:63-8.

30. Lim J, Bhoo-Pathy N, Sothilingam S, Malek R, Sundram M, Tan GH, et al. Cardiovascular risk factors and ethnicity are independent factors associated with lower urinary tract symptoms. PLoS One 2015;10: e0130820. 